\title{
0 acesso do indivíduo às instâncias de proteção do Sistema Africano de Proteção dos Direitos do Homem e dos Povos*
}

\section{Individual access to the instances of African Protection System for the Protection of Human Rights and Peoples}

\section{Resumo}

O presente artigo tem por objetivo analisar e refletir sobre o acesso do indivíduo a instâncias de proteção Sistema Africano de Proteção dos Direitos do Homem e dos Povos, quais sejam, a Comissão Africana e a Corte Africana dos Direitos do Homem e dos Povos. Primeiramente, apresentamos breve referência ao indivíduo enquanto sujeito de direito internacional e, em seguida, explanamos acerca das instâncias de proteção do Sistema Africano de Proteção, analisando, de forma direta, o acesso do indivíduo a estas instâncias e citando jurisprudências relativas. Finalmente, procedemos a uma análise comparativa do acesso individual aos três sistemas regionais de proteção. Por meio da dogmática jurídica, demonstramos que existe um direito de demanda individual perante a Comissão e a Corte Africana, porém, tal acesso não possibilita a realização incondicionada e plena desse direito, uma vez que ele, na Corte Africana, só poderá ser exercido se o Estado demandado tiver reconhecido a competência da Corte para apreciar feitos individuais, cláusula facultativa de jurisdição, que tolhe o exercício desse direito, já que, na prática, nenhum Estado violador tem interesse de reconhecer a competência da Corte para ser demandado. Concluímos também que, em relação aos três sistemas regionais de proteção dos direitos do homem, o sistema europeu é o que se revela mais democrático, haja vista que assegura o acesso direto a todo e qualquer indivíduo à sua jurisdição.

Palavras-chave: Acesso. Indivíduo. Corte Africana. Comissão Africana. Direitos do homem.

\begin{abstract}
This article aims to analyze and reflect on the individual's access to instances of protecting African System of Protection of Human Rights and Peoples, namely, the African Commission and African Court of Human Rights and Peoples. First, we present a brief reference to the individual as subject of international law and then expounded on the instances of protection of African System Protection, analyzing, directly, the individual's access to these instances and on citing case law. Finally, we undertook a comparative analysis of individual access to three regional systems of protection. Through legal dogmatics, we demonstrated that there is an individual right to demand before the Commission and African Court, however, such access does not
\end{abstract}

* Artigo recebido em 21/08/2011 Aprovado em 11/10/2011

Mestranda em Direitos Fundamentais pela Faculdade de Direito de Lisboa - Portugal; Professora de Direito Civil das Faculdades Integradas de Patos. Advogada. 
allow the unconditional and full realization of this right, as this, the African Court can only be exercised if the Respondent has recognized the Court's jurisdiction to appreciate individual claims, optional clause of jurisdiction, which hinders the exercise of this right, since, in practice, no violator state has an interest to recognize the Court's competence to be sued. We also conclude that in the three regional systems of protection of human rights, the European system is more democratic, as it guarantees direct access to any person within its jurisdiction.

Keywords: Access. Individual. African Court. African Commission. Human Rights.

\section{Introdução}

O continente africano tem sido palco de graves violações de direitos humanos ao longo dos últimos cinco séculos. No entanto, entre as décadas de 1970 e 1980, principalmente com a pressão verificada pela multiplicação das Organizações não Governamentais (ONGs) nos Estados africanos, os governos foram forçados a rever as políticas e leis ofensivas aos direitos humanos básicos. Nessa seara, a comunidade internacional passou a assistir uma avalanche de mecanismos internacionais de resolução de litígios. ${ }^{2}$

Inicialmente, os líderes africanos foram favoráveis à criação de Comissões quase judiciais para resolução de litígios, ao invés da criação de uma Corte com plenos poderes. Esse fato derivou, por um lado, da força do Direito Consuetudinário Africano, no qual há a valorização das relações entre as partes na base da equidade, da boa consciência em detrimento da estrita legalidade. Por outro lado, esse favorecimento às Comissões ocorreu em virtude da relutância dos governos africanos emergentes que enxergavam na possibilidade de uma Corte - uma instituição supranacional, clara ameaça à independência e soberania duramente conquistada.

Entretanto, diante da ineficácia dessas instituições na proteção dos direitos humanos no continente africano, mormente da Comissão Africana dos Direitos do Homem e dos Povos, criada pela Carta Africana dos Direi-

2 UDOMBANA, Nsongurua J. An African Human Rights Court and an African Union Court: a needful duality or a needless duplication? Brooklyn Journal of International Law, n. 28, p. 2, mês abreviado 2003. tos do Homem e dos Povos, nasceu a ideia de uma Corte Africana, buscando implementar um sistema regional de direitos humanos dotado de uma instituição forte que ancorasse suas normas.

Assim sendo, em 09 de junho de 1998, em sua trigésima quarta sessão ordinária, realizada em Burkina Faso, a Assembleia dos Chefes de Estado e de Governo da extinta Organização da Unidade Africana (OUA) adotou um Protocolo à Carta Africana dos Direitos do Homem e dos Povos para a constituição da Corte Africana dos Direitos do Homem e dos Povos.

Por outro lado, em 11 de julho de 2000, em sua trigésima sexta sessão ordinária realizada em Lome, Togo, a OUA aprovou o Ato Constitutivo da União Africana (UA) para substituir a Organização da Unidade Africana e reforçar a Comunidade Econômica Africana, prevendo a criação de uma Corte de Justiça da União Africana, efetivamente proposta no Protocolo da Corte de Justiça da União Africana, adotado em julho de 2003.

Entretanto, em $1^{\circ}$ de julho de 2008, foi adotado o Protocolo relativo ao Estatuto da Corte Africana de Justiça e Direitos Humanos, resultante da fusão da Corte Africana dos Direitos do Homem e dos Povos e da Corte de Justiça da União Africana.

Ocorre que, como até o presente momento, não houve o depósito dos instrumentos de ratificação por quinze Estados-Membros, o Protocolo Adicional à Carta Africana dos Direitos do Homem e dos Povos permanecerá em vigor durante esse período transitório para permitir que a Corte Africana dos Direitos do Homem e dos Povos possa implementar as medidas necessárias para a transferência de suas prerrogativas, bens, direitos e obrigações para a futura Corte Africana de Justiça e Direitos Humanos.

Assim, tendo em vista as atuais instâncias de proteção do Sistema Africano de Proteção dos Direitos do Homem e dos Povos, quais sejam, a Comissão Africana e a Corte Africana dos Direitos do Homem e dos Povos, propomos na presente investigação analisar e refletir sobre o acesso do indivíduo a essas instâncias de proteção, baseando-nos nos instrumentos que as criaram, isto é, a Carta Africana dos Direitos do Homem e dos Povos e o Protocolo Adicional à Carta Africana dos Direitos do Homem e dos Povos.

Portanto, como dito, o prisma da investigação é a perspectiva do indivíduo nas referidas instâncias de 
proteção, sendo as demais, tais quais, a das organizações não governamentais, dos Estados etc. apenas citadas quando assim forem necessárias. Essa delimitação pode ser justificada, primeiro, pelo fato do indivíduo ter emergido da Segunda Guerra Mundial sob o holofote do Direito Internacional, com o reconhecimento de direitos individuais em diversos tratados de Direitos Humanos, a aceitação de mecanismos de queixas individuais, a capacidade individual para reclamar graves violações de direitos humanos perante a Corte Penal Internacional pela Ex-Iugoslávia, Ruanda e o princípio da jurisdição universal, segundo, porque foi principalmente por intermédio das queixas individuais que a atuação da Organização da Nações Unidas e dos instrumentos regionais de proteção dos direitos humanos foi incrementado, mormente no sistema africano; ${ }^{3}$ terceiro, porque consideramos o indivíduo como sujeito de direito internacional, que, embora venha gradualmente conquistando seu espaço como tal, não possui acesso pleno e incondicionado às instâncias de proteção dos direitos humanos, não somente no âmbito africano.

Tendo em vista o objeto, traçamos os seguintes objetivos: de forma geral, buscaremos investigar e refletir acerca do acesso do indivíduo à Comissão Africana e à Corte Africana de Proteção e Defesa dos Direitos do Homem e dos Povos, conhecendo, de forma genérica, o Sistema Regional Africano de Proteção dos Direitos do Homem e dos Povos, estudando as particularidades das suas instâncias de proteção, analisando e comparando a realidade africana com a experiência europeia e americana no tocante ao acesso do indivíduo.

Por meio da dogmática jurídica, almejamos responder os seguintes questionamentos: existe um direito de demanda individual perante a Comissão e a Corte Africana? Caso a resposta seja positiva, o acesso a essas instâncias de proteção possibilita a concretização, a eficácia desse direito? Quais as condições desse acesso? O Protocolo que estabeleceu a Corte Africana favoreceu a recepção de demandas individuais em relação à Comissão Africana? Como ocorre o acesso do indivíduo na Corte Interamericana e na Corte Europeia dos Direitos do Homem? Comparando-se as três experiências, qual tribunal possibilita de forma mais democrática esse acesso?

3 VILJOEN, Frans. A Human Rights Court for Africa and Africans. Brooklin Journal of International Law, p. 2, 2004.
Vale ressaltar que, embora a atenção do trabalho esteja centrada no Sistema Africano de Proteção dos Direitos do Homem, merecerá pontual referência o enquadramento da temática no sistema europeu e interamericano, para fins comparativos.

Os métodos utilizados na investigação foram o técnico-jurídico e o correlacional ou comparativo, visto que abordaremos o tema de forma crítica e reflexiva, sem nos limitarmos à mera descrição. Além disso, traçaremos uma análise comparativa do acesso do indivíduo às instâncias africanas de proteção dos direitos do homem e dos povos com a experiência americana e europeia. $\mathrm{O}$ estudo se pautará na investigação doutrinária, legal e jurisprudencial acerca do acesso do indivíduo à Comissão Africana e à Corte Africana dos Direitos do Homem e dos Povos.

\section{0 indivíduo como sujeito de direito internacional e seu direito de acesso à justiça internacional}

A corrente doutrinal do positivismo tradicional representada por Triel e Anzilotti, sustentava que apenas os Estados eram sujeitos do Direito Internacional Público. Entretanto, como o Estado foi criado pelos seres humanos e é por eles composto, não há o que questionar que em casos de violação aos direitos do homem, justifica-se o acesso direto do indivíduo à jurisdição internacional para fazer salvaguardar seus direitos, inclusive contra o próprio Estado.

O indivíduo deve ser visto, assim, tanto como sujeito de direito interno como internacional.

No período logo após a Segunda Guerra Mundial, quando agressões aos direitos e liberdades inerentes aos seres humanos foram cometidas pelas atrocidades e horrores daquela época, um interesse internacional em promover e encorajar o respeito pelos direitos humanos emergiu e um plano internacional de ação positiva foi reivindicado. Direitos humanos passaram a integrar as exigências mais elementares de convivência na sociedade internacional. Com a Carta das Nações Unidas, de 1945, houve a necessidade de se criarem recursos ante instâncias internacionais de controle e garantia, não só de promoção, mas também de proteção dos direitos humanos.

$\mathrm{O}$ indivíduo aparece em um primeiro momento como detentor de direitos a serem reconhecidos pelo Di- 
reito Internacional. Com o passar dos anos, ele conquista, direta ou indiretamente, capacidade postulatória frente às Cortes Internacionais, mormente às de Direitos do Homem.

E é nesse sentido que Wladimir de Brito entende que se o indivíduo pode assegurar a defesa de seus direitos perante órgãos internacionais, então é possível afirmar que ele possui personalidade e capacidade jurídica internacional, sendo nessa medida, um sujeito do direito internacional. $^{4}$

Para Celso de Albuquerque Mello, invocando a dignidade da pessoa humana como governante da ordem jurídica no que tange ao reconhecimento dos direitos fundamentais do homem e sua respectiva proteção, bem como a própria noção de Direito, que consiste na obra do homem para o próprio homem, defende a personalidade jurídica do indivíduo, alegando que não se pode falar em direitos do homem garantidos pela ordem jurídica internacional se o homem não for sujeito de direito internacional. ${ }^{5}$

No tocante à subjetividade jurídica internacional do indivíduo, Cançado Trindade ${ }^{6}$ ensina que carecem plenamente de sentido as tentativas do passado de negar aos indivíduos a condição de sujeitos do direito internacional, por não lhe serem reconhecidas algumas das capacidades de que são detentores os Estados, como por exemplo, a de celebrar tratados. Tampouco no plano do direito interno, nem todos os indivíduos participam, direta ou indiretamente, no processo legiferante, e nem por isso deixam de ser sujeitos de direito.

De acordo com o referido autor, o reconhecimento dos direitos individuais deve estar diretamente relacionado à capacidade processual de postulá-los, tanto no plano interno como internacional, de tal modo que é mediante à sua consolidação que a proteção dos direitos humanos passa a se tornar uma realidade.

${ }^{4}$ BRITO, Wladimir. Direito internacional público. Coimbra: Coimbra Ed., 2008.

5 MELLO, Celso D. de Albuquerque. Curso de direito internacional público. Rio de Janeiro: Renovar, 2004.

6 TRINDADE, Antônio Augusto Cançado. A Personalidade e Capacidade Jurídicas do Indivíduo como Sujeito do Direito Internacional. In: ANNONI, Danielle (Org.). Os novos conceitos do novo direito internacional: cidadania, democracia e direitos humanos. Rio de Janeiro: América Jurídica, 2002. p. 6.
Embora não haja unanimidade entre os doutrinadores no que tange à subjetividade do indivíduo, é evidente que a tendência é de ser cada vez mais atribuído ao indivíduo o locus standi no cenário mundial, a partir da capacidade postulatória que lhe é conferida, em se tratando da tutela dos direitos humanos, nos planos global e regional.

Seguindo a linha de Jonatas Machado, para quem defende o indivíduo como unidade primária e por excelência do direito internacional, passaremos a analisar, se o sistema africano permite ao indivíduo o seu acesso junto às instâncias de proteção, mormente no tocante à capacidade processual de postular e salvaguardar seus direitos, salientando que o acesso à justiça não compreende apenas o direito do indivíduo de peticionar aos tribunais, mas sim, de uma garantia de direito, no sentido de tornar possível sua materialização. ${ }^{7}$

\section{Das instâncias de proteção}

O discurso dos direitos humanos na África assume nova dimensão com a adoção da Carta Africana dos Direitos do Homem e dos Povos, também conhecida como Carta de Banjul, em Nairóbi, em 27 de junho de 1981, pela Assembleia dos Chefes de Estado e de Governo da Organização da Unidade Africana, a qual foi posteriormente transformada em União Africana, em 25 de Maio de 2002. ${ }^{8}$ Assim, o Sistema Africano de Direitos do Homem está ancorado na referida Carta, um instrumento que é largamente promocional com função dupla de promoção, e, conforme Makau Mutua, de nenhum mecanismo credível. Para esse autor, isso não é surpreendente, haja vista que praticamente nenhum Estado africano, com as exceções de Gâmbia, Senegal e Botswana orgulhavam-se de uma democracia nominal, em 1981, ano de aprovação do aludido instrumento. ${ }^{9}$

A Carta nasceu da convicção dos Estados africanos pela necessidade de um compromisso regional de

7 MACHADO, Jónatas E. M. Direito internacional: do paradigma clássico ao pós-11 de setembro. 3. ed. Coimbra: Coimbra Ed., 2006.

8 AFRICA UNION. [Site]. Disponível em: <www.africa-union. org $>$.

9 MUTUA, Makau. The African Human Rights Court: A twolegged stool? In: HUMAN rights quarterly: the Jonhs Hopkins Universit. 1999. p. 1. 
direitos humanos à luz dos padrões internacionais estabelecidos pela Declaração Universal dos Direitos Humanos, outra norma posterior de criação de instrumentos internacionais de direitos humanos e a experiência de outras regiões.

Além disso, os Estados africanos, que tinham estado por muito tempo preocupados com as suas lutas contra a dominação colonial, perceberam que, após mais de duas décadas do fim do colonialismo, existia uma necessidade de organização para a proteção dos direitos da pessoa humana contra as violações de seus próprios governos. Embora essas afirmações possam fornecer algumas das razões subjacentes à promulgação da Carta, a situação dos direitos humanos em muitos países africanos, naquela época, era problemática: o totalitarismo estava no ar, quer sob a forma de governos militares ou autocracias; e essa ameaça ensejava a maior parte do clamor regional e internacional para a necessidade de uma ação concreta.

A Carta Africana contempla meios de salvaguarda dos direitos e deveres que estabelece o funcionamento de dois órgãos de proteção dos direitos do homem e dos povos, quais sejam: a Comissão Africana dos Direitos Humanos e dos Povos, de natureza técnica-jurisdicional e política, e a Corte Africana dos Direitos do Homem e dos Povos, de natureza jurídica-jurisdicional, de acordo com o doutrinador Marcolino Moco. ${ }^{10}$ Vejamos.

\subsection{Da Comissão Africana dos Direitos do Homem e dos Povos}

\subsubsection{Breves considerações}

A Comissão Africana dos Direitos do Homem e dos Povos se encontra em exercício desde 1987 e tem como sede, Gâmbia, tendo alternado suas sessões entre essa cidade e outras capitais africanas. É composta por 11 membros (artigo 30 e 31) e a integração é feita a título pessoal, sendo eleitos por um período de seis anos renováveis (artigo 36) e um presidente e vice-presidente por um período de dois anos igualmente renováveis.
De acordo com a Carta Africana dos Direitos do Homem e dos Povos, a Comissão Africana dos Direitos do Homem e dos Povos é detentora de competência para promover os direitos do homem e dos povos e assegurar sua respectiva proteção, consoante prevê o artigo 30, contemplando, portanto, uma dupla função, qual seja: de promoção e de proteção dos Direitos do Homem e dos Povos.

No tocante à competência da Comissão Africana, tendo em vista o disposto no artigo 45 da Carta, cabe a ela promover os direitos do homem e dos povos; fazer estudos e pesquisas; formular princípios e regras; assegurar a proteção dos direitos humanos e dos povos; recorrer a métodos de investigação; criar relatorias temáticas específicas; adotar resoluções no campo dos direitos do homem e interpretar os dispositivos da Carta Africana.

Como mencionamos acima, a Comissão Africana possui dupla função: a de promoção e a de proteção. No que tange à primeira, materializa-se por meio de visitas dos membros da Comissão aos países africanos, incluindo a pesquisa e a difusão de informações por intermédio de seminários e simpósios, de produção de relatórios, de incentivo das autoridades nacionais e locais, de instituições de direitos humanos, de formulação de princípios para resolver problemas jurídicos em matéria de direitos humanos e de cooperação com instituições africanas e internacionais de direitos humanos.

No que concerne à função de proteção, ela ocorre, mormente, por duas vias: os relatórios dos Estados e as comunicações interestatais e individuais. No sistema de relatórios, os Estados se comprometem a apresentar de dois em dois anos um relatório sobre as medidas de ordem legislativa ou outra, tomadas com vista a efetivar os direitos e as liberdades reconhecidas e garantidas pela Carta. O Regimento da Comissão determina a forma e o conteúdo dos relatórios estaduais, espelhando as lições de outros organismos de direitos humanos, conforme aponta Makau Mutua ${ }^{11}$. As orientações foram complementadas com Diretrizes Gerais, um documento inédito que foi enviado aos ministros dos Negócios Estrangeiros

${ }^{11}$ MUTUA, Makau. The African Human Rights Court: A twolegged stool? In: HUMAN rights quarterly: the Jonhs Hopkins University. 1999.
MOCO, Marcolino José Carlos. Direitos humanos e seus mecanismos de proteção: as particularidades do sistema africano. Coimbra: Almedina, 2010. p. 216. 
dos Estados-Partes, em 1990. As diretivas são apenas um resumo das orientações. ${ }^{12}$

Em relação às comunicações, tendo em vista o disposto nos artigos 47 a 49 da Carta, compete à Comissão apreciar comunicações interestatais que denunciem violação aos direitos do homem e dos povos enunciados na Carta, haja vista o previsto nos seus artigos 55 a 59, buscando sempre uma solução amistosa. Não sendo nosso objeto de estudo, tais comunicações não merecem maior aprofundamento, o qual só será dado às comunicações individuais que serão tratadas no tópico seguinte.

\subsubsection{Do seu acesso pelo indivíduo: as comunicações individuais}

A Carta Africana não prevê expressamente a possibilidade de comunicações individuais perante a Comissão, como bem lembra Umozurique. Foi mediante uma interpretação dinâmica da categoria "Outras comunicações", mencionada no artigo 55 da Carta, que a Comissão Africana conseguiu desenvolver sua competência em relação às comunicações individuais. ${ }^{13}$ Assim, salienta Marcolino Moco, que embora a Carta utilize uma terminologia vaga, a designação de comunicações individuais se revela apropriada, mormente por ser utilizada no sistema universal de proteção dos direitos humanos. ${ }^{14}$

Marcolino Moco ressalta que no tocante à referência autoral dessas comunicações, deve-se valer de uma interpretação aberta, devendo integrar, portanto, na legitimidade, para apresentar as comunicações previstas no supracitado artigo da Carta, não só as pessoas individuais, mas também grupo de pessoas ou associações, como as ONGs, aceitando-se que essas entidades possam apresentar comunicações em nome das vítimas. ${ }^{15}$

${ }^{12}$ MUTUA, Makau. The African Human Rights Court: A twolegged stool? In: HUMAN rights quarterly: the Jonhs Hopkins University. 1999. p. 2-3.

${ }^{13}$ UMOZURIKE, U. O. The African Charter on Human and People's Rights: Suggestions for more effectiveness. Annual Survey of International \& Comparative Law: golden gate university school of law, spring 2007.

${ }^{14}$ MOCO, Marcolino José Carlos. Direitos humanos e seus mecanismos de proteção: as particularidades do sistema africano. Coimbra: Almedina, 2010.

${ }^{15}$ Ibidem, p. 229.
Comunga do mesmo entendimento Makau $\mathrm{Mu}$ tua, o qual defende que, com essa expressa, a Carta não impôs nenhuma restrição para quem possa apresentar uma comunicação individual. Para o supramencionado autor, essa falta de restrição criou uma abertura que permite a qualquer indivíduo, grupos ou ONGs, ou não, vítimas diretas da alegada violação, para apresentar uma petição. ${ }^{16}$ É também o entendimento de Curtis F. J. Doebbler, para quem não há exigência alguma de que a pessoa ou entidade que apresenta a queixa seja vítima da violação ou esteja a residir no país contra a qual a denúncia é feita. ${ }^{17}$

Assim, antes de cada sessão, o secretário da Comissão estabelece a lista das comunicações individuais e comunica aos membros da Comissão, os quais poderão apreciá-las a pedido da maioria absoluta dos seus membros.

Importa mencionar que a Comissão interpreta nessa expressão a autorização de lidar não só com flagrante e maciça violação dos direitos humanos, mas também com casos isolados de violações dos direitos humanos, conforme salienta Fatsah. ${ }^{18}$

A Carta Africana não contém quaisquer disposições delineando o processo de comunicação individual, embora Makau Mutua saliente que a fórmula da Comissão para considerar comunicações individuais tenha formato semelhante ao do Comitê de Direitos Humanos, o qual organiza as suas decisões em seções lidando com os fatos, os argumentos, a admissibilidade das provas, o mérito do caso e a conclusão final. ${ }^{19}$ Entretanto, na ausência de uma disposição legal, a Comissão procurou, na verdade, inspiração no artigo 52 da Carta, que diz respeito às comunicações interestaduais.

${ }^{16}$ MUTUA, Makau. The African Human Rights Court: A twolegged stool? In: HUMAN rights quarterly: the Jonhs Hopkins University. 1999. p. 3.

${ }^{17}$ DOEBBLER, Curtis F. J. The African Union and the new panafricanism: rushing to organize or timely shift: A complex ambiguity: the relationship between the African Commission on Human and Peoples' Rights and Other African Union Initiatives Affecting respect for Human Rights. Transnational Law and Contemporary Problems. n. 13, p. 4, 2003.

${ }^{18}$ OUGUERGOUZ, Fatsah. The African Charter on Human and Peoples' Rights: a comprehensive agenda for human dignity and sustainable democracy in Africa. 2003.

${ }^{19}$ MUTUA, Makau. The African Human Rights Court: A twolegged stool? In: HUMAN rights quarterly: the Jonhs Hopkins University. [S.l: s.n], 1999. p. 3. 
Assim, a Comissão, ao receber os pedidos, deve buscar desenvolver "uma solução amigável" com todos os meios adequados antes de preparar um relatório sobre suas conclusões e recomendações.

É naturalmente questionável se um procedimento interestadual, como o estabelecido pelo artigo 52, com vista a solucionar disputas interestaduais entre as partes soberanas, muitas vezes, ocorre por meio de prescrições políticas, é uma fonte de inspiração apropriada para as comunicações individuais. Essa dúvida existe porque, muitas vezes, implica-se um processo de comunicação quase judicial interposto perante a Comissão, por indivíduos ou ONGs contra os Estados que fazem parte da Carta.

Dessa forma, considerando a Comissão que o objetivo primordial do processo de comunicação é dar início a um diálogo positivo, resultando em uma solução amigável entre o queixoso e o Estado em questão, tem elegido como requisitos para efetivação desse objetivo a boa fé das partes envolvidas, incluindo a sua disponibilidade para participar de um diálogo. Tais requisitos para obtenção de uma resolução amigável na comunicação individual dependem tanto de critérios subjetivos quanto de objetivos. Como parte do critério subjetivo, a Comissão exige que a resolução deva possibilitar a satisfação de ambas as partes; e o critério objetivo é duplo, ambas as partes são chamadas a agir de boa fé para obter uma resolução. Podemos verificar esse escopo principal da Comissão, nas Comunicações no 16, 17 e 18 de 1988, demandados por Comitê Culturel pour la Democratie au Benin, Hilaire Badjogoume, El Hadj Boubacare Diawara em face do Benin.

Importa salientar que, para serem examinadas, as comunicações individuais devem preencher certas condições de admissibilidade. Abordaremos tais condições de forma breve, uma vez que é mais relevante para o estudo que propusemos abarcar as questões de competência e acesso do que de admissibilidade.

O artigo 56 da Carta Africana elenca os requisitos de admissibilidade das comunicações individuais, quais sejam: indicação da identidade do seu autor, mesmo que haja a solicitação dele à Comissão pela manutenção do anonimato; ser compatível com a Carta da Organização da Unidade Africana ou com a Carta Africana; não conter termos ultrajantes ou insultuosos para com o Estado impugnado, as suas instituições ou a Organização da Uni- dade Africana; não se limitar a reunir informações divulgadas por meios de comunicação de massa; esgotamento prévio das vias internas, salvo no caso de demora injustificada; observância de um prazo razoável para apresentação da petição e a inexistência de litispendência internacional.

Como primeiro requisito, temos a indicação da identidade do autor da comunicação individual, mesmo que ele tenha solicitado o anonimato junto à Comissão Africana. Esse fato se mostra óbvio frente à necessidade de se informar acerca dos elementos essenciais da queixa ao Estado demandado. Analisando-se os casos submetidos à Comissão, não foi verificado nenhum que houvesse requerido anonimato.

Como segundo requisito, temos a compatibilidade da comunicação individual com a Carta da OUA ou com a Carta Africana dos Direitos do Homem e dos Povos. Marcolino Moco, citando Franz Viljoen, alerta que a conjunção disjuntiva "ou" deve ser lida como a copulativa "e", combinando os dois instrumentos como requisitos em relação aos quais as comunicações devem ser compatíveis. Outrossim, Marcolino Moco chama atenção para o fato de que o princípio da compatibilidade implica uma série de consequências da admissibilidade, tais como: a pressuposição de que um direito previsto na Carta foi violado por um Estado-Parte; os fatos lesivos ocorreram no período de vigência da Carta e que os fatos tenham ocorrido dentro do território do Estado sob queixa ou sob a sua autoridade. ${ }^{20}$

Como terceiro requisito, temos o fato de que a redação da comunicação individual não deve ser feita em linguagem insultuosa e ultrajante contra o Estado demandado, as suas instituições e a OUA. Essa condição é bastante criticada pela doutrina internacional, uma vez que favorece o afastamento da comunicação pela utilização de expressões mais veementes, o que beneficia os Estados violadores.

Como quarto requisito, temos que a comunicação não deve estar baseada exclusivamente em fatos veiculados pela mídia. Esse ponto é relevante principalmente no sistema africano que não exige a condição de vítima para ser autor de uma comunicação individual.

\footnotetext{
${ }^{20}$ MOCO, Marcolino José Carlos. Direitos humanos e seus mecanismos de proteção: as particularidades do sistema africano. Coimbra: Almedina, 2010. p. 237.
} 
Como quinto requisito, temos o esgotamento prévio das vias internas, dos recursos jurisdicionais, como reflexo do princípio da subsidiariedade da lei internacional em relação à lei nacional. Assim, parte-se da premissa de que se deve dar oportunidade ao Estado para poder cumprir com as suas obrigações internas, sendo a intervenção das instituições internacionais, eminentemente complementar. Dessa forma, uma comunicação individual não será admitida pela Comissão Africana se não provar que se recorreu a todas as instâncias internas e que o caso não está pendente em nenhum delas. Importa mencionar que se o processo atinente aos recursos internos se prolongar de forma anormal, isto é, se houver uma demora injustificada, então o pressuposto da admissibilidade estará cumprido.

Como sexto requisito, temos o fato de que deve decorrer um prazo razoável entre o esgotamento das vias internas e a submissão da comunicação individual. A Carta Africana não indica qual seria esse prazo, diferentemente das Convenções Europeia e Americana que especificam o prazo de seis meses.

Como último requisito, temos a inexistência de decisão anterior sobre o mesmo caso, isto é, permite-se uma concorrência de tratamento de um mesmo caso em instâncias de diferentes níveis, até que surja a primeira decisão.

É cabível, ainda, mencionar uma questão interessante que é colocada por grande parte da doutrina, qual seja: o silêncio do indivíduo implica o desejo dele de se retirar da comunicação.

Embora hoje a Comissão Africana entenda que, sempre que o queixoso for um indivíduo, a Comissão não pode interpretar automaticamente o silêncio como a retirada da comunicação, porque os indivíduos são altamente vulneráveis às circunstâncias que possam impedi-los de continuar a prosseguir em uma comunicação. Mas, lamentavelmente, a Comissão ainda não desenvolveu a prática de pedir provas que permitam uma análise das razões pelas quais vários autores não conseguiram continuar a sua comunicação com a Comissão. Tal fato já ocorreu no caso no 11/88 Henry Kalenga v. Zâmbia. O autor da comunicação tinha sido mantido em detenção sem julgamento desde 27 de fevereiro de 1986. Ele trouxe sua queixa à Comissão em 2 de agosto de 1988, exigindo a sua libertação imediata, mas a Comissão não recebeu qualquer informação dele. No entanto, em 5 de março de 1991, o Ministério de Assuntos Jurídicos da Zâmbia, informou à Comissão que o queixoso tinha sido liberado em 1989. Agindo com base nas informações fornecidas pelo Estado-Parte, e sem consultar o autor da comunicação, a Comissão adotou o ponto de vista que a liberação do autor da comunicação da prisão havia sanado o prejuízo invocado e constituiu uma solução amigável.

Faz-se mister mencionar ainda que muitos fatores têm impactado na efetividade da Comissão Africana como um todo e não somente em relação às comunicações individuais. São deficiências de natureza normativa e estrutural que repercutem de forma bastante negativa na Comissão Africana enquanto instituição de proteção e defesa dos direitos do homem e dos povos na África. Vejamos.

A Comissão não possui independência plena para exercer suas funções. No exame das comunicações individuais se mostra muito menos independente do que nas interestatais, haja vista que só pode realizar um estudo detalhado, a pedido da Assembleia dos Chefes de Estado e de Governo.

Há também um controle político muito grande exercido pela Assembleia à Comissão. Rachel Murray menciona a falta de independência em relação aos Estados, que pode ser comprovada, ao longo da história, por conexões de vários de seus 11 membros com os governos, sendo alguns deles até mesmo embaixadores. Martorana, citando Udombana e Nmehielle, exemplifica que dois altos funcionários do governo do Congo, um Estado que viola de forma desenfreada os direitos humanos, atuaram como comissionários. ${ }^{21}$

Outra questão que reflete de forma crucial na efetividade da Comissão Africana é o fato de ser intermitente, posto que só possui sessões ordinárias semestrais, por dez dias, sem contar também com as suas limitações orçamentárias, já que a União Africana passa por grandes dificuldades financeiras e é a provedora direta das atividades da Comissão Africana.

Podemos aludir também a confidencialidade das deliberações da Comissão Africana. Apesar da disposição

${ }^{21}$ MARTORANA, Carolyn Scanlon. The new African Union: will it promote enforcement of the decisions of the African Court of Human and Peoples Rights? George Washington International Review, n. 40, p. 596, 2008. 
de imunidade diplomática e a não responsabilidade dos comissários no artigo 43, o artigo 59 prevê que todas as medidas tomadas no âmbito das disposições da Carta devem permanecer confidenciais até que a Assembleia dos Chefes de Estado e de Governo decida diferentemente. Além disso, os relatórios da Comissão só serão publicados após a Assembleia analisá-los. Esses fatos deixam clara a existência de conflitos de interesse por parte dos membros da Assembleia, já que ela não autorizou a publicação de qualquer relatório da Comissão até o início da União Africana, como salienta Martorana. ${ }^{22}$

Também vale mencionar a desconsideração das resoluções da Comissão Africana pelos Estados-Partes, já que suas recomendações não têm valor vinculativo jurídico e não acarretam a aplicação de qualquer indenização, restauração ou aplicação de condenação ao Estado agressor, ficando a vítima sem qualquer reparação, como bem enfatiza Nsongurua J. Udombana. ${ }^{23}$

Na verdade, a Carta não prevê quaisquer mecanismos de aplicação para implementar as recomendações da Comissão, após o relatório feito para os estados envolvidos, conforme previsto no artigo 52 ou depois que aquela realiza um estudo aprofundado nos termos do artigo 58. ${ }^{24}$ Assim, em qualquer caso, nem a Carta nem a Comissão preveem soluções exequíveis ou um mecanismo para incentivar e acompanhar o cumprimento das decisões pelo

${ }^{22}$ MARTORANA, Carolyn Scanlon. The new African Union: will it promote enforcement of the decisions of the African Court of Human and Peoples Rights? George Washington International Review, n. 40, p. 597, 2008.

${ }^{23}$ Afirma Nsongurua J. Udombana "Its decisions and recommendations to African Heads of States and Governments are frequently disregarded. As a report of the African Commission pointed out, "with the sovereignty of the Assembly of Heads of State and Government and the Charter's non-provision of alternative methods of compensation for victims of Human Rights violations, the said victims find themselves without any remedy." Such noncompliance constitutes "one of the major factors of the erosion of the Commission's credibility,"because it undermines the authority of the Commission as an effective institution capable of ensuring the states' implementation of the rights secured in the African Charter. UDOMBANA, Nsongurua J. An African Human Rights Court and an African Union Court: a needful duality or a needless duplication? Brooklyn Journal of International Law, n. 28, p. 5, 2003.

${ }^{24}$ MARTORANA, op. cit, p. 595.
Estado. Desse modo, as conclusões da Comissão são muito remotas, senão praticamente insignificantes. ${ }^{25}$

Embora a Comissão Africana não tenha adotado nenhum mecanismo de cumprimento sistemático de suas recomendações por parte do Estado violador, em certos momentos, alguns comissários se comprometeram a fazer um acompanhamento, de forma limitada, em uma base ad hoc. O exemplo mais notável foram os questionamentos dirigidos pelo Comissário Jainaba Johm aos Estados em relação à execução de suas decisões em matéria de comunicações individuais durante a análise de relatórios do Estado. ${ }^{26}$ Tais medidas, entretanto, eram isoladas.

\subsection{Da Corte Africana dos Direitos do Homem e dos Povos}

\subsubsection{Breves considerações}

Em virtude, principalmente, da ineficácia da Comissão Africana no tocante à proteção dos direitos humanos, verificada, mormente, pelos descumprimentos das suas recomendações pelos Estados-Partes, a comunidade internacional passou a defender a criação de uma Corte Africana dos Direitos do Homem e dos Povos capaz de emitir decisões de caráter jurídico obrigatório.

De acordo com Makau Mutua ${ }^{27}$, havia duas correntes para criação de uma Corte Africana dos Direitos do Homem e dos Povos. Uma corrente sustentava que a Corte deveria ser estabelecida o mais rapidamente possível para salvar o sistema de sua irrelevância quase total e obscuridade. As deficiências normativas e institucionais do Sistema Africano seriam tão incapacitantes que somente a criação de uma Corte efetiva de Direitos Humanos poderia iniciar seu processo de redenção.

Por outro lado, a outra corrente vislumbrava o trabalho do Sistema Africano principalmente como de promoção e não judicante. Segundo esta visão, o maior problema na África seria a falta de conscientização da população em geral dos seus direitos e dos processos para reivindicar esses direitos. Os defensores dessa corrente

\footnotetext{
${ }^{25}$ MUTUA, Makau. The African Human Rights Court: A twolegged stool? In: HUMAN rights quarterly: the Jonhs Hopkins University. 1999. p. 4.

${ }^{26}$ VILJOEN, Frans. A Human Rights Court for Africa and Africans. Brooklin Journal of International Law, p. 6, 2004.

${ }^{27}$ Ibidem.
} 
argumentavam que o sistema regional deveria primeiramente educar o público com a promoção dos direitos humanos, sendo a tarefa de proteção, que incluiria a criação de uma Corte de direitos humanos, menos urgente. Os críticos defendiam que uma Corte poderia ser assolada pelos mesmos problemas que vinham afetando a Comissão Africana, razão pela qual seria mais apropriado reforçar a Comissão Africana, solucionando suas falhas do que criar outro órgão, possivelmente impotente. ${ }^{28}$

Nos últimos anos, esta última visão deu lugar para os defensores de uma Corte Africana de Direitos do Homem e dos Povos. Tornou-se evidente em meados da década de 1990 que o Sistema Africano, dado sua inoperância, era um embaraço para o continente.

Foram vários encontros que antecederam a criação do Protocolo, dentre eles, podemos citar a reunião de peritos na Etiópia em 1997, cuja discussão girou entorno da questão do locus standi, ou seja, de quem poderia propor petições junto ao tribunal. O consenso estabelecido resultou da pretensão da maioria dos representantes dos Estados no encontro, que reduziu a legitimidade das ONGs tituladas com o estatuto de observador junto à Comissão e os indivíduos de nacionalidades dos Estados que, nos termos do artigo $34, n^{\circ} 6$, optassem por reconhecer esta prerrogativa aos seus nacionais.

Assim, em 1998, foi adotado o Protocolo à Carta Africana objetivando a criação da Corte Africana dos Direitos do Homem e dos Povos, em Addis Abeba, na Etiópia. O Protocolo entrou em vigor em 25 de janeiro de 2004, com o depósito do $15^{\circ}$ instrumento de ratificação, conforme dispõe o seu artigo 34, tendo sido celebrado unanimemente pela comunidade dos defensores dos direitos humanos.

Makau Mutua salienta que a simples adição de uma Corte, embora seja um desenvolvimento significativo, é pouco provável, que por si só, seja suficiente para solucionar as deficiências estruturais e normativas que têm assolado o Sistema Africano de Proteção dos Direitos do Homem desde a sua criação. ${ }^{29}$ Entretanto, ressalta o aludido autor que a criação dessa Corte vai ajudar a promover os direitos humanos internacionais em outras regiões

${ }^{28}$ MUTUA, Makau. The African Human Rights Court: A twolegged stool? In: HUMAN rights quarterly: the Jonhs Hopkins University. [S.l: s.n], 1999. p. 5.

${ }^{29}$ Ibidem, p. 1. do mundo, como na Ásia, onde há clara resistência à aplicação e interiorização do corpus dos direitos humanos e onde até o momento não há nenhum sistema regional de direitos humanos.

Adentrando no referido Protocolo, verificamos que, de acordo com o seu artigo 25, a sede da Corte Africana dos Direitos do Homem e dos Povos será determinada pela Conferência dos Chefes de Estado e de Governo, de um dos Estados-Partes do Protocolo, podendo ser alterada pela Conferência após consultas com o próprio tribunal. Atualmente, a sede reside em Arusha, Tanzânia, onde funciona o seu cartório.

A Corte Africana é composta por 11 juízes nacionais dos Estados-Membros da União Africana, devendo ser eleitos, a título individual, entre juristas de alto caráter moral, com reconhecida prática, competência judicial ou acadêmica e experiência no domínio dos Direitos $\mathrm{Hu}$ manos, conforme preconiza o artigo 11 do Protocolo. A Corte deve apresentar uma representação equilibrada das principais regiões africanas bem como de suas principais tradições jurídicas. ${ }^{30}$

A Corte tem apenas uma Câmara e examina os casos submetidos, desde que tenha um quorum de sete juízes, sendo suas sentenças inapeláveis, com fulcro nos artigos 23 e 28, nº 2, do Protocolo Adicional à Carta Africana.

Consoante se verifica no Preâmbulo do Protocolo, a Corte tem por escopo fortalecer a proteção dos direitos humanos e dos povos contemplados na Carta Africana, de modo a "complementar e fortalecer as funções da Comissão Africana”. Makau Mutua assevera que nesse ponto do Protocolo se verifica claramente a essência da fraqueza e incompletude da Comissão Africana, que passa a requerer o funcionamento da Corte de modo a suprir suas falhas. ${ }^{31}$

Como vimos, cabe à Corte Africana complementar o mandato da Comissão Africana, nos moldes do artigo $1^{\circ}$ da Carta, conjugando a competência consultiva com a contenciosa. Em relação àquela, a Corte poderá emitir opiniões consultivas acerca da interpretação de dispositivos

\footnotetext{
${ }^{30}$ UDOMBANA, Nsongurua J. An African Human Rights Court and an African Union Court: a needful duality or a needless duplication? Brooklyn Journal of International Law, n. 28, p. 7, 2003.

${ }^{31}$ MUTUA, Makau. The African Human Rights Court: A twolegged stool? In: HUMAN rights quarterly: the Jonhs Hopkins University. [S.l: s.n], 1999. p. 6.
} 
da Carta Africana ou de qualquer outro instrumento relevante de direitos do homem, por solicitação dos Estados da União Africana, da própria União Africana e de seus órgãos ou de qualquer organização africana reconhecida pela União Africana, conforme prevê o artigo $4^{\circ}$ do Protocolo.

No que concerne à competência contenciosa, a Corte apreciará, de forma automática, casos submetidos pela Comissão Africana, por Estado ou por organização intergovernamental africana, consoante prevê o artigo $5^{\circ}$ do Protocolo. Os indivíduos também poderão submeter casos junto à Corte, só que de forma facultativa, como veremos no tópico seguinte.

Vale salientar que o aludido Protocolo prevê que a Corte Africana deverá conduzir os procedimentos publicamente, embora possa também realizar audiências em câmera, nos casos especificamente delineados pelo Regimento.

\subsubsection{Do seu acesso pelo indivíduo}

Os indivíduos e as ONGs poderão submeter casos diretamente à Corte, se houver declaração formulada pelo Estado para esse fim, conforme preconiza os artigos $5^{\circ}$, parágrafo $3^{\circ}$, e 34 , parágrafo $6^{\circ}$, do Protocolo. ${ }^{32}$ Atualmente, apenas Burkisa Faso e Mali elaboraram a declaração a que faz menção o artigo $5^{\circ}$, parágrafo $3^{\circ}$, do Protocolo, razão pela qual Viljoen considera que, sendo a declaração opcional, o acesso direto do indivíduo à Corte Africana constitui, na verdade, exceção e não a regra. ${ }^{33}$

Assim, diferentemente da Carta Africana, observa-se que o Protocolo Adicional à Carta Africana expressamente prevê a possibilidade de demanda diretamente à Corte pelo indivíduo. Entretanto, duas condições são postas: a primeira é o reconhecimento pelo Estado da competência da Corte Africana para receber demandas individuais, configurando-se, portanto, como uma cláu-

\footnotetext{
${ }^{32}$ Artigo $5^{\circ}, \mathrm{n}^{\circ} 3$. The Court may entitle relevant Non Governmental Organizations (NGOs) with observer status before the Commission, and individuals to institute cases directly before it, in accordance with article 34 (6) of this Protocol.

Artigo 34, $\mathrm{n}^{\circ} 6$. At the time of the ratification of this Protocol or any time thereafter, the State shall make a declaration accepting the competence of the Court to receive cases under article 5 (3) of this Protocol. The Court shall not receive any petition under article 5 (3) involving a State Party which has not made such a declaration. AFRICAN COURT ON HUMAN AND PEOPLES’ RIGHTS. [Site]. Disponível em: <www.african-court. org/fileadmin/documents $>$. Acesso em: 10 jun. 2010.

${ }^{33}$ VILJOEN, Frans. A Human Rights Court for Africa and Africans. Brooklin Journal of International Law, p. 9, 2004.
}

sula facultativa prevista no artigo $34, n^{\circ} 6$. A segunda condição é que a declaração deve ser anterior ao recebimento das demandas individuais pela Corte.

Nesse aspecto, Viljoen alerta que o artigo $5^{\circ}, \mathrm{n}^{\circ} 3 \mathrm{e}$ o artigo 34, n ${ }^{\circ} 6$ do Protocolo Adicional à Carta Africana, da forma como se encontram estabelecidos ("may entitle"), não devem ser interpretados de modo a fornecer à Corte Africana critério adicional para recusar a apreciação de um caso. A concessão à Corte Africana de um poder discricionário para recusar demandas individuais seria excessivamente prejudicial ao indivíduo, haja vista que o acesso dependeria de dois grandes obstáculos processuais: a declaração do Estado e a aprovação da Corte Africana. ${ }^{34}$

Uma questão interessante suscitada por Mubiala é se a Corte precisará da referida declaração caso a caso. Para o autor, esse entendimento seria uma interpretação restritiva do dispositivo, contrariando o interesse da proteção dos direitos do homem que milita em favor de uma interpretação dinâmica dessa disposição, razão pela qual defende que a Corte Africana deveria fixar no seu Regulamento Interno as condições gerais dessas demandas. ${ }^{35}$

Makau Mutua considera uma grave lacuna do Protocolo à Carta Africana dos Direitos do Homem e dos Povos a limitação de acesso à Corte Africana dos Direitos do Homem e dos Povos pelos indivíduos e ONGs. Entretanto, reconhece que este limite foi necessário para que o Protocolo obtivesse as assinaturas necessárias para sua ratificação. ${ }^{36}$ No mesmo sentido, salientou Udombana, para quem esta disposição foi um compromisso político para induzir os Estados a ratificarem o Protocolo. ${ }^{37}$

Na verdade, a limitação do acesso pelos indivíduos e ONGs foi um verdadeiro golpe no prestígio e reputação da Corte Africana dos Direitos do Homem e dos Povos, mormente aos olhos dos africanos, haja vista que são os

\footnotetext{
${ }^{34}$ VILJOEN, Frans. A Human Rights Court for Africa and Africans. Brooklin Journal of International Law, p. 9, 2004.

${ }^{35}$ MUBIALA, Mutoy. Laccès de l'individu à la Cour Africaine des droits de l'homme et des peuples. In: PROMOTING justice, human rights and conflict resolution through international law: liber amicorum lucius caflisch. [S.l: s.n], 2007. p. 369-378.

${ }^{36}$ MUTUA, Makau. The African Human Rights Court: A twolegged stool? In: HUMAN rights quarterly: the Jonhs Hopkins University. [S.1: s.n], 1999. p. 6.

${ }^{37}$ Ibidem, p. 6.
} 
indivíduos e ONGs e não a Comissão Africana, entidades intergovernamentais ou os Estados, os principais beneficiários e usuários da Corte.

Como se sabe, a grande proposta da Corte não pretendia que ela fosse uma instituição para a proteção dos direitos dos Estados ou dos órgãos da Unidade Africana, mas sim essencialmente uma Corte de direitos humanos que protegesse a pessoa humana contra as violações dos Estados e outras agências estatais. Tal limitação tem reduzido de forma crucial o papel da Corte Africana na proteção dos Direitos do Homem e dos Povos. Tal fato pode ser corroborado com a análise da própria jurisprudência da Corte, a qual julgou apenas um caso até o presente momento, como verificaremos no tópico seguinte.

Outrossim, parece bastante incongruente que os indivíduos tenham legitimidade para demandar, de forma direta e incondicionada, seus governos perante os tribunais nacionais, mas não possam fazê-lo perante uma Corte Internacional, como a Corte Africana dos Direitos do Homem e dos Povos, posto que tal faculdade fica à mercê de uma declaração do Estado violador. ${ }^{38}$

Ademais, no tocante ao acesso do indivíduo, é cabível mencionar ainda a necessidade da gratuidade da representação legal dele perante a Corte Africana. O artigo $10, \mathrm{n}^{\circ} 2$, do Protocolo estabelece o direito de qualquer parte de ser representada por um representante legal de sua escolha, devendo a representação legal gratuita ser assegurada quando os interesses da justiça assim o requererem. Essa disposição merece ser refletida, principalmente em um continente onde os cidadãos vivem em situação de pobreza humilhante, podendo a falta de recursos financeiros para custear a representação legal constituir para o indivíduo outro óbice na defesa de seus direitos. ${ }^{39}$ Para Mubiala, a União Africana deveria financiar todo mecanismo de assistência judiciária, sendo tal medida indispensável para a distribuição de uma justiça igualitária perante a Corte Africana. ${ }^{40}$

${ }^{38}$ UDOMBANA, Nsongurua J. An African Human Rights Court and an African Union Court: a needful duality or a needless duplication? Brooklyn Journal of International Law, n. 28, p. 9, 2003.

${ }^{39}$ Ibidem, p10.

${ }^{40}$ MUBIALA, Mutoy. Laccès de l'individu à la Cour Africaine des droits de l'homme et des peuples. In: PROMOTING justice, human rights and conflict resolution through international law: liber amicorum lucius caflisch. [S.l: s.n], 2007. p. 5.

\subsubsection{Do seu contributo jurisprudencial}

É de grande relevância para este estudo analisar a única decisão da Corte Africana até o presente momento, pelas seguintes razões: primeiro, porque a parte demandante é um indivíduo; segundo, porque muitas questões são suscitadas a respeito dos dispositivos do Protocolo Adicional à Carta Africana dos Direitos do Homem e dos Povos referentes à competência da Corte Africana bem como do acesso do indivíduo a essa instância de proteção; por último, porque tal julgado é capaz de nos revelar o olhar da Corte numa perspectiva futura.

A decisão consiste no julgado de $n^{\circ} 001 / 2008$, submetido por Michelot Yogogombabaye em face da República do Senegal. ${ }^{41}$

De forma breve, podemos dizer que o requerente entrou com a petição junto à Corte Africana em face da República do Senegal em 11 de agosto de 2008. Em 5 de janeiro de 2009, Senegal foi citado para comunicar o nome e o endereço dos seus representantes legais, tendo o requerente em carta datada de 30 de janeiro de 2009, informado que seria seu próprio representante.

Por fax, no dia 10 de fevereiro de 2009, Senegal enviou à Corte o nome e endereço dos seus representantes.

Em 17 de fevereiro de 2009, Senegal requereu à Corte Africana que estendesse o prazo para contestar melhor o pleito do requerente, o que foi deferido pela Corte. Após isso, Senegal contestou o pleito do requerente, à admissibilidade do pleito, bem como problemas materiais.

Instado a se manifestar, o requerente não respondeu, tendo a Corte o intimado a responder no prazo de 30 dias, sob pena da Corte Africana considerar falta de interesse, de acordo com o artigo 52, no 5 . Logo após, o requerente se manifestou, reiterando o que foi dito na

petição inicial, declarando não haver nada a acrescentar. A Corte então decidiu se reunir para deliberação.

Pela decisão da Corte, o requerente alegou que o Senegal, ao assinar o Protocolo, teria reconhecido automaticamente a competência da Corte para receber petições individuais. Em contrapartida, Senegal alegou que,

\footnotetext{
${ }^{41}$ AFRICAN COURT ON HUMAN AND PEOPLES' RIGHTS. [Site]. Disponível em: <www.african-court.org >. Acesso em: 13 jun. 2010.
} 
para a Corte receber petições individuais, seria necessário que o Estado-Parte reconhecesse primeiramente essa competência específica da Corte, conforme prevê o artigo 34, no 6, do Protocolo Adicional, o que não ocorreu no caso, já que Senegal não fez a referida declaração, sendo, a petição inadmissível.

De acordo com as regras, a Corte antes de adentrar no mérito, deveria analisar as preliminares alegadas, mormente,as que questionassem a jurisdição da Corte.

Combinando o artigo $5^{\circ}, \mathrm{n}^{\circ} 3$ que confere às ONGs com status de observadoras e a indivíduos a prerrogativa de submeter-lhe casos diretamente com o artigo 34, $n^{\circ} 6$, que diz que no momento da ratificação do Protocolo ou em qualquer momento, o Estado poderá fazer uma declaração aceitando a competência da Corte para receber casos diretamente dos indivíduos, não podendo a Corte receber qualquer petição nesses termos envolvendo Estado que não tiver elaborado a declaração, e após receber diretamente da Comisssão a lista dos Estados que fizeram a declaração, a Corte verificou a ausência dela por parte do Senegal, razão pela qual entendeu não possuir competência para apreciar o caso.

A Corte salientou que, embora a parte Senegal tivesse alegado o fundamento de inadmissibilidade, na verdade, o que tinha havido era falta de competência da Corte.

Dessa decisão e mormente da opinião separada do juiz Fatsah Ourguegouz ${ }^{42}$, pudemos extrair esclarecimentos acerca dos artigos $5^{\circ}, n^{\circ} 3$ e 34 , que como já vimos, referem-se especificamente à possibilidade da demanda individual perante a Corte.

De acordo com Ourguegouz, o termo receber presente na segunda sentença do artigo $34, n^{\circ} 6$, não pode ser interpretado no seu sentido literal (como receber fisicamente) nem no sentido técnico (como admissibilidade), deve, ao invés, ser interpretado à luz da letra e do espírito do artigo de forma geral e em particular, em relação à expressão "declaração aceitando a competência da Corte para receber casos diretamente dos indivíduos e ONGs". Fica evidente que o objetivo do referido artigo é prescre-

\footnotetext{
${ }^{42}$ OURGUEGOUZ, Fatsah. Separate opinion of judge Fatsah Ouguergouz. Disponível em: <www.african-court.org/fileadmin/documents/Court/Latest_Judgments/English/SEPARATE_OPINION_OF_JUDGE_FATSAH_OUGUERGOUZ. EN.PDF>. Acesso em: 15 jun. 2010. Tradução livre.
}

ver as condições para Corte Africana apreciar esses casos, quer dizer, a exigência de uma declaração especial deve ser depositada pelo Estado parte em questão e expor as consequências da falta desse depósito por parte do Estado em causa. Dessa forma, tendo a Corte Africana concluído que não tinha competência para julgar o caso, não havia necessidade para analisar a questão da admissibilidade.

Para o autor, o requerente tem o direito de saber porque aguardou um ano da entrada do seu requerimento até a decisão em que a Corte apenas reconheceu não ter competência para o caso, bem como Senegal o direito de saber porque ao invés de ter seguido o procedimento, a Corte não rejeitou de plano o caso.

Primeiramente, diferentemente do que ocorre na Comissão Africana (em que nenhuma comunicação individual é recebida se for contra Estado que não seja parte da Carta, de acordo com art. 102 e 103 do Regimento), na extinta Comissão da União Europeia, na Comissão Interamericana, em que as comunicações passam por um processo de controle prévio para serem registradas ou notificadas aos Estados contra os quais foram instituídas, na Corte Africana, mais especificamente nessa decisão, o pedido foi recebido pela Secretaria, colocado na lista geral, seguidamente Senegal, o Presidente da Comissão da União Africana, bem como as outras partes do Protocolo foram informados da petição, sem qualquer controle prévio.

Fatsah Ourguegouz lembra que esse caso foi tratado da mesma forma como as petições perante o Tribunal Internacional de Justiça antes de $1^{\circ}$ de julho de 1978, data da entrada em vigor das suas novas regras. Antes dessa data, todos os casos trazidos perante o Tribunal, incluindo os instaurados contra os Estados que não haviam aceitado a jurisdição do Tribunal, por meio da declaração opcional aceitando a jurisdição compulsória prevista no artigo 36, $\mathrm{n}^{\circ} 2$ do Estatuto, foram efetivamente colocados na lista geral e dirigidos aos Estados contra os quais foram instituídos, e ao Secretário-Geral das Nações Unidas e, por meio dele, aos outros membros da organização.

Esse fato não deveria ocorrer para se tornar mais operacional, evitando dar publicidade intempestiva ou indevida às petições individuais em relação às quais a Corte é manifestamente incompetente. Nessa hipótese, menciona Fatsah Ourguegouz, o pedido deveria ter sido rejeitado de plano, por carta simples pelo Registro. 
Senegal, em uma primeira oportunidade, informou a Corte acerca de seus representantes e seus endereços; em um segundo momento, requereu a Corte prazo maior para oferecer contestação; e só apenas no terceiro ato processual, questionou a "admissibilidade" do pleito, quando já no primeiro momento poderia ter se limitado a indicar que não havia feito a declaração prevista no artigo 34, no 6, do Protocolo, e que, portanto, a Corte não tinha competência para apreciar o caso nos termos do artigo $5^{\circ}, n^{\circ} 3$, do Protocolo. Ourguegouz questiona se tendo agido dessa forma, por duas vezes, sem ter o Estado contestado a competência da Corte, não teria implicitamente a reconhecido.

Fatsah Ourguegouz lembra que o princípio fundamental em matéria de aceitação da jurisdição de um tribunal internacional é do consentimento, um princípio que é derivado da soberania do Estado. O consentimento do Estado é a condição sine qua non para a jurisdição de qualquer tribunal internacional, independentemente do momento ou da maneira como o consentimento foi expresso. Ao se tornarem partes do Protocolo, os Estados-Membros da União Africana aceitam, consequentemente, a jurisdição da Corte Africana para receber petições de outros Estados-Partes, da Comissão Africana e Organizações Africanas Intergovernamentais. Em relação à jurisdição da Corte para receber petições de indivíduos ou ONGs como parte não é automática, depende da declaração facultativa de consentimento dos Estados em questão.

Ao analisar o artigo 34, no 6, Fatsah Ourguegouz chama atenção para duas questões: a primeira é o sentido da palavra "shall" usada na primeira sentença que sugere que a apresentação da declaração por parte do Estado-Parte é uma obrigação e não simplesmente uma questão de escolha. Compreendido desse modo, o artigo 34 tornaria obrigatória para os Estados-Partes fazerem essa declaração após o depósito dos seus instrumentos de ratificação (ou adesão). Isso, contudo, não teria qualquer efeito jurídico real, haja vista que não há o estabelecimento de qualquer limite de tempo.

Também não faz muito sentido quando lido à luz do seu contexto e, em especial do artigo $5^{\circ}, \mathrm{n}^{\circ} 3$, segunda frase, do $34, n^{\circ} 6$, que afirma que a Corte não poderá receber qualquer petição nos termos do artigo $5^{\circ}, n^{\circ} 3$ envolvendo Estado que não tiver elaborado tal declaração. Assim, pode-se dizer, em conclusão que o preenchimento da declaração é opcional, o que pode ser corroborado por uma análise dos trabalhos preparatórios do Protocolo.

A segunda questão levantada no artigo $34, n^{\circ} 6$ é a de saber se a apresentação da declaração facultativa pelos Estados-Partes é o único meio de expressar o seu reconhecimento da competência do tribunal para tratar dos pedidos contra eles pelos indivíduos.

A esse respeito, o autor salienta que $\mathrm{o}$ artigo $34, \mathrm{n}^{\circ}$ 6 não exige que o preenchimento da declaração opcional seja feito antes da apresentação do pedido, mas apenas determina que a declaração pode ser feita no momento da ratificação ou a qualquer momento daí em diante. Nada impede, portanto, que um Estado-Parte faça a declaração após o pedido ser apresentado contra ele. No artigo 34, $\mathrm{n}^{\circ} 4$ do Protocolo, depreende-se que a declaração, assim como a ratificação ou adesão, entra em vigor a partir da data de apresentação e produz efeitos a partir dessa mesma data. Senegal era, portanto, no caso em análise, livre para fazer essa declaração mesmo depois que a petição fora apresentada.

Se um Estado pode aceitar a jurisdição do Tribunal mediante a apresentação de uma declaração opcional em qualquer momento, nada no Protocolo impede seu consentimento, após a apresentação da petição, de uma forma que não por meio da declaração opcional. Tal possibilidade é, por exemplo, codificada nos termos do artigo 62, parágrafo $3^{\circ}$, da Convenção Americana de Direitos Humanos bem como no artigo 48 da Convenção Europeia dos Direitos Humanos antes do Protocolo 11.

Portanto, a segunda frase do artigo 34, $\mathrm{n}^{\circ} 6$ não deve, como a primeira sentença, ser interpretada literalmente. Deve ser lida à luz do objeto e finalidade do Protocolo Adicional e, em particular, à luz do artigo $3^{\circ}$ intitulado "jurisdição da Corte". Com efeito, o artigo $3^{\circ}$ prevê de maneira geral, que "a jurisdição do Tribunal deve alcançar todos os casos e disputas lhe forem submetidos", e também que "em caso de disputa quanto à jurisdição da Corte, cabe a Corte decidir". Assim, cabe à Corte determinar em toda a soberania as condições para a validade da sua apreensão, e fazê-lo apenas à luz do princípio do consentimento.

O Consentimento pelo Estado-Parte é a única condição para que o Tribunal tenha jurisdição no que diz respeito a petições apresentados pelos indivíduos. Esse consentimento pode ser expresso antes da apresentação 
de uma petição contra o Estado-Parte, com a apresentação da declaração referida no artigo $34, n^{\circ} 6$ do Protocolo. Ele também pode ser expresso mais tarde, ou formalmente, pela apresentação de tal declaração, ou informalmente ou implicitamente por intermédio do forum prorogatum.

Forum prorogatum, como bem explica Fatsah Ourguegouz, pode ser entendido como a aceitação da jurisdição de um tribunal internacional por um Estado, após a demanda na Corte por outro Estado ou indivíduo, e que ela ocorra, expressa ou tacitamente, por meio de atos decisivos, ou por um comportamento inequívoco. Foi em particular essa possibilidade que ocorreu com as cartas emitidas pelo Senegal, dias 10 e 17 de fevereiro de 2009 que levaram a Corte a prever isso, no presente caso. Só após 9 de abril é que Senegal alegou que não tinha intenção de aceitar a jurisdição da Corte para apreciar petição individual. Só então a Corte quis pôr termo à demanda e retirá-la da lista geral.

Por Senegal ter formalmente apresentado objeções preliminares em sua contestação datada de 09 de abril, a Corte considerou a necessidade de respeitar as disposições da regra $52^{\circ}, \mathrm{n}^{\circ} 7$, do seu Regulamento que estipula que "o tribunal deve fundamentar a sua decisão sobre a questão prévia”.

Assim, a Corte, considerando as preliminares arguidas por Senegal, passou a abordar a questão da competência de uma forma mais abrangente, desenvolvendo, nomeadamente, a possibilidade de um forum prorogatum. E é essa possibilidade que de certa forma explica a razão pela qual a petição do requerente não foi rejeitada depois de 10 de fevereiro, momento em que Senegal informou o nome e endereço de seus representantes e a apresentação de preliminares e a razão pela qual a Corte não encerrou o caso de maneira menos solene por uma ordem ou carta do registro, de acordo com o que discorreu Ourguegouz.

\subsubsection{Situação atual da Corte Africana e perspectivas futuras}

Muitas questões têm impactado na efetividade da Corte Africana. Uma questão apontada, é que os autores em potencial de petições individuais podem apresentar dificuldades, na experiência de circunstâncias atuais, de conhecer a situação do Estado africano no tocante à declaração opcional. Na verdade, apenas a lista de EstadosPartes do Protocolo está publicada no site da Corte e tal lista não menciona os Estados que tenham feito a decla- ração opcional, sendo necessário que tal lista seja igualmente publicada, informando aos indivíduos e as ONGs a respeito.

Reflete diretamente na efetividade da Corte também o fato de só 25 dos 53 Estados da União Africana terem ratificado o Protocolo e apenas Burkina Faso e Mali terem feito a declaração reconhecendo a jurisdição da Corte em relação às demandas individuais.

Outro fator que pode ser apontado é o fato de a Corte Africana não ser permanente, já que só se reúne quatro vezes por ano, cada sessão por quinze dias e só o juiz presidente trabalha em tempo integral, os outros dez só trabalham em tempo parcial.

Uma questão que também refletirá diretamente no sistema de proteção africano, mormente, na Corte Africana, é a criação do Tribunal de Justiça da União Africana, por intermédio de um Protocolo Adicional, adotado em 11 de julho de 2003, por força das previsões orgânicas do Ato Constitutivo da União Africana (artigo 18) que ainda não entrou em vigor.

De acordo com o site da União Africana, em 20 de junho de 2010, apenas 16 Estados da União Africana haviam ratificado e depositado o instrumento legal respectivo. ${ }^{43} \mathrm{O}$ artigo 13 impõe a maioria de dois terços de ratificações dos 53 Estados-Partes da União Africana como condição para entrada em vigor do instrumento jurídico.

Em relação ao acesso do indivíduo ao Tribunal de Justiça da União Africana, o referido Protocolo não faz menção expressa. O artigo 18, do aludido Protocolo dispõe:

Article 18

\section{ELIGIBILITY TO SUBMIT CASES}

1. The following are entitled to submit cases to the Court:
(a) States Parties to this Protocol;
(b) The Assembly, the Parliament and other or- gans of the Union
authorised by the Assembly;

(c) The Commission or a member of staff of the Commission in a dispute between them within the limits and under the conditions laid down in the Staff Rules and Regulations of the Union;

\footnotetext{
${ }^{43}$ AFRICAN COURT ON HUMAN AND PEOPLES' RIGHTS. [Site]. Disponível em: <www.african-court.org > Acesso em: 17 jun. 2010.
} 
(d) Third Parties under conditions to be determined by the

Assembly and with the consent of the State Party concerned.

2. The conditions under which the Court shall be open to third parties shall, subject to the special provisions contained in treaties in force, be laid down by the Assembly, but in no case shall such conditions place the parties in a position of inequality before the Court. 3. The States which are not members of the Union shall not be allowed to submit cases to the Court. The Court shall have no jurisdiction to deal with a dispute involving a Member State that has not ratified this Protocol. (grifo nosso) $^{44}$

Como se pode depreender do artigo supracitado, não há alusão ao acesso ao Tribunal pelo indivíduo, defendendo parte da doutrina, que a legitimidade do indivíduo estaria prevista na alínea d que se refere aos terceiros.

Em julho de 2008, a União Africana adotou formalmente um instrumento jurídico único para criar um Tribunal Africano de Justiça e Direitos Humanos, o chamado Protocolo relativo ao Estatuto do Tribunal Africano de Justiça e Direitos Humanos, resultante da fusão do Tribunal Africano dos Direitos do Homem e dos Povos e do Tribunal de Justiça da União Africana. A decisão de fundir os dois tribunais foi da Assembleia dos Chefes de Estado e de Governo da União Africana, em junho de 2004, com o fito de garantir recursos suficientes para financiar um tribunal único e eficaz no continente africano.

Este Protocolo único substitui o Protocolo à Carta Africana dos Direitos do Homem e dos Povos que estabeleceu a Corte Africana dos Direitos do Homem e dos Povos, adotada em 1998 e o Protocolo do Tribunal de Justiça da União Africana que foi aprovada em 2003.

O Protocolo Adicional à Carta Africana permanecerá em vigor durante um período transitório para permitir que a Corte Africana dos Direitos do Homem e dos Povos possa implementar as medidas necessárias para a transferência de suas prerrogativas, bens, direitos e obrigações para o Tribunal Africano de Justiça e Direitos Humanos. O Protocolo só entrará em vigor trinta dias após o depósito dos instrumentos de ratificação por quinze Estados-Membros.

${ }^{44}$ AFRICAN COURT ON HUMAN AND PEOPLES' RIGHTS. [Site]. Disponível em: <www.african-court.org >. Acesso em: 17 jun. 2010.
Pelo Protocolo de 2008, possuem capacidade para postular perante o Tribunal de Justiça os Estados-Partes, a Comissão Africana dos Direitos do Homem e dos Povos, o Comitê Africano de Peritos sobre os Direitos e Bem-Estar da Criança, as organizações intergovernamentais africanas e as instituições africanas dos Direitos Humanos. Contudo, indivíduos e ONGs só podem apresentar apenas petições contra os Estados que tenham feito uma declaração aceitando e reconhecendo a competência do Tribunal de Justiça para fazê-lo, nos termos do artigo 30, alínea f, do Protocolo único. Assim, ao menos que os Estados façam tal declaração, essa limitação torna ilusório o acesso à justiça para as vítimas de direitos humanos, conforme verificamos dos seguintes artigos do referido Protocolo:

Article 8

Signature, Ratification and Accession

1. The present Protocol shall be open for signature, ratification or accession by Member States, in accordance with their respective constitutional procedures.

2. The instruments of ratification or accession to the present Protocol shall be deposited with the Chairperson of the Commission of the African Union.

3. Any Member State may, at the time of signature or when depositing its instrument of ratification or accession, or at any time thereafter, make a declaration accepting the competence of the Court to receive cases under Article 30 (f) involving a State which has not made such a declaration.

Article 30

Other Entities Eligible to Submit Cases to the Court

The following entities shall also be entitled to submit cases to the Court on any violation of a right guaranteed by the African Charter, by the Charter on the Rights and Welfare of the Child, the Protocol to the African Charter on Human and Peoples' Rights on the Rights of Women in Africa, or any other legal instrument relevant to human rights ratified by the States Parties concerned:

a) State Parties to the present Protocol;

b) the African Commission on Human and Peoples' Rights;

c) the African Committee of Experts on the Rights and Welfare of the Child;

d) African Intergovernmental Organizations accredited to the Union or its organs;

e) African National Human Rights Institutions; 
f) Individuals or relevant Non-Governmental Organizations accredited to the African Union or to its organs, subject to the provisions of Article 8 of the Protocol. ${ }^{45}$

Como se vê, mesmo nesse Protocolo Único, a questão do acesso do indivíduo à instância de proteção continua a ser um motivo de preocupação que ameaça a eficácia do Tribunal. Faz-se necessário que a sociedade civil, os Estados e a União Africana busquem intensificar esforços no sentido de instar os Estados a ratificarem o Protocolo Único bem como fazer a declaração permitindo o acesso do indivíduo ao Tribunal.

É importante mencionar que o Protocolo relativo ao Estatuto do Tribunal Africano de Justiça e Direitos Humanos ainda não se encontra em vigor, estando tal fato condicionado ao depósito dos instrumentos de ratificação por 15 Estados-Partes. Em consulta ao site da União Africana em 20 de junho de 2010, pudemos constatar que até o momento, apenas a Líbia e Mali ratificaram o aludido Protocolo. ${ }^{46}$

\section{A experiência das Cortes Europeia e Intera- mericana}

No tocante ao acesso do indivíduo à Corte Europeia dos Direitos Humanos, o fato é que, originariamente, a Convenção Europeia dos Direitos Humanos não contemplou o acesso direto pelo indivíduo à jurisdição especializada, como reflexo da concepção clássica de que no Direito Internacional os conflitos devem se limitar aos Estados.

No formato original da Convenção, o acesso à Corte Europeia se limitava às Altas Partes Contratantes e a Comissão Europeia, conforme previa o artigo 44, sob a condição de os Estados-Partes declararem formalmente o reconhecimento da jurisdição obrigatória da Corte, tendo em vista o que dispunha o artigo 46 da Convenção. Dessa forma, o indivíduo que se considerasse vítima de violação cometida por uma das Partes Contratantes dos Direitos contemplados na referida Convenção, formalizavam a

\footnotetext{
${ }^{45}$ AFRICAN COURT ON HUMAN AND PEOPLES' RIGHTS. [Site]. Disponível em: <www.african-court.org >. Acesso em: 17 jun. 2010.

${ }^{46}$ Ibidem.
}

queixa perante o Secretário-Geral do Conselho da Europa (artigo 25). À Comissão, competia conhecer do requerimento apresentado ao Secretário-Geral, sendo requisito para o processamento pela Comissão Europeia da petição individual, o reconhecimento explícito da Alta Parte Contratante acusada da competência da Comissão na matéria, conforme previa o artigo $25, \mathrm{n}^{\circ} 1$ da Convenção.

Em um segundo momento, o indivíduo ainda não possuía o direito de pleitear diretamente seus direitos perante a jurisdição regional de proteção dos direitos do homem. A legitimidade para tal ficava restrita à Comissão e às Altas Partes Contratantes, sendo assegurado, entretanto, ao requerente, o lócus standi in judicio, isto é, embora não pudesse inaugurar o processo, possuía o direito de estar em juízo, de ser parte no processo e de participar de sua condução perante a Corte. Essa prerrogativa surgiu com o advento da reforma do Regulamento, introduzida em 24 de novembro de 1982 e com a vigência a partir de $1^{\circ}$ de janeiro de 1983 .

Em um terceiro momento, o Protocolo no 9 da Convenção Europeia de Direitos Humanos, aberto à assinatura em 06 de novembro de 1990 e em vigor a partir de $1^{\circ}$ de outubro de 1994 , veio introduzir a possibilidade de o indivíduo submeter sua queixa perante a Corte Europeia, desde que atendidas as condições de admissibilidade, quais sejam: a provocação pelo indivíduo da Comissão Europeia para o desenvolvimento da apuração preliminar prevista no artigo 25, seguida de manifestação positiva desse órgão no tocante à existência de violação e à submissão da queixa individual à apreciação prévia de um Comitê de três juízes da Corte, que exerceria um juízo de admissibilidade negativo.

O Protocolo $n^{\circ}$ 11, adotado em Estrasburgo em 11 de maio de 1994 e que entrou em vigor em $1^{\circ}$ de novembro de 1998, veio a consagrar definitivamente o acesso direto do indivíduo à Corte Europeia dos Direitos Humanos. Por meio da Recomendação no 1194/1992, a Assembleia Consultiva aprovou a proposta de uma Corte Europeia única e permanente, já que, como vimos, anteriormente ao supracitado Protocolo, existiam a Comissão Europeia dos Direitos Humanos e a Corte Europeia dos Direitos Humanos. Portanto, houve a reestruturação do sistema de proteção da Convenção Europeia, que integrou a Comissão e a Corte em uma jurisdição única denominada Corte Europeia dos Direitos do Homem. 
A principal inovação em relação ao procedimento desse Protocolo, contudo, consiste no abandono da cláusula facultativa de aceitação anterior da jurisdição obrigatória da Corte Europeia, abrindo assim a via de demanda de plano pelo indivíduo, não se podendo mais impor às petições individuais as limitações constantes do Protocolo $\mathrm{n}^{\circ} 09$ no que tange às exigências especiais de admissibilidade. Como bem salienta a jurista Flávia Piovesan, essa reforma permitiu igualmente à Corte Europeia se tornar mais profissional e eficaz e menos politizada. ${ }^{47}$

No que concerne à experiência interamericana, $\mathrm{o}$ acesso do indivíduo à Corte Interamericana de Direitos Humanos segue a mesma evolução da Corte Europeia, mas a passos mais lentos. Hodiernamente, a Corte Interamericana de Direitos Humanos ultrapassou a fase na qual a Comissão Interamericana detinha a função de defesa dos interesses individuais, com o domínio integral sobre o ingresso da causa e os cuidados com sua instrução, tendo estacionado, entretanto, no reconhecimento do locus standi in judicio a parte individual.

Os representantes da vítima eram designados assistentes, admitindo o artigo 22 do Regulamento da Corte Interamericana de 1991, que os delegados da Comissão fossem assistidos por qualquer pessoa de sua escolha, mas se os advogados da vítima estivessem entre as pessoas selecionadas, o fato deveria ser levado ao conhecimento dos membros da Corte. Em 1997, houve uma reforma do Regulamento que passou a prever a possibilidade de o representante da vítima tomar parte nas discussões orais e, na fase de reparação, seus representantes podiam submeter de forma independente seus próprios argumentos e provas.

Com o advento da reforma do Regulamento da Corte Interamericana em 2001, houve a consolidação do regime do locus standi in judicio, assegurando à parte individual a participação direta na condução do processo. Assim, com esse novo Regulamento, ainda que indivíduos e ONGs não tenham acesso direto à Corte, se a Comissão Interamericana submeter o caso a esta, as vítimas, seus parentes ou representantes podem submeter de forma autônoma seus argumentos, arrazoados e provas perante a Corte.

${ }^{47}$ PIOVESAN, Flávia. Direitos humanos e justiça internacional: um estudo comparativo dos sistemas regionais europeu, interamericano e africano. São Paulo: Saraiva, 2007.
Cabe à Comissão Interamericana de Direitos Humanos examinar as comunicações encaminhadas por indivíduo ou grupo de indivíduos, ou ainda entidade não governamental que contenham denúncia de violação a direito consagrado pela Convenção, por Estado que dela seja parte, nos termos dos artigos 44 e 41.

O Estado, ao se tornar parte da Convenção, aceita automática e obrigatoriamente a competência da Comissão para examinar essas comunicações, não sendo necessário elaborar qualquer declaração expressa e específica para tal fim. No sistema interamericano, portanto, apenas a Comissão Interamericana e os Estados-Partes podem submeter um caso à Corte Interamericana, não estando prevista a legitimação do indivíduo, nos moldes do artigo 61 da Convenção Americana.

De acordo ainda com o novo Regulamento da Comissão, se a Comissão considerar que o Estado em questão não cumpriu as recomendações do informe aprovado nos termos do artigo 50 da Convenção Americana, submeterá o caso à Corte Interamericana, salvo decisão fundada da maioria absoluta dos membros da Comissão. Se, anteriormente, cabia à Comissão Interamericana, a partir de uma avaliação discricionária, sem parâmetros objetivos, submeter à apreciação da Corte Interamericana caso em que não se obteve solução amistosa, com o novo Regulamento, o encaminhamento à Corte se faz de forma direta e automática. Importa salientar que a decisão da Corte tem força jurídica vinculante e obrigatória, cabendo ao Estado seu imediato cumprimento. Todavia, é necessário que o Estado reconheça a jurisdição da Corte, já que tal jurisdição é apresentada sob a forma de cláusula facultativa.

No que tange à experiência africana, como vimos, o acesso direto pelo indivíduo à Corte Africana dos Direitos do Homem e dos Povos é expressamente previsto no Protocolo Adicional à Carta Africana dos Direitos do Homem e dos Povos. Entretanto, tal acesso depende do reconhecimento por parte dos Estados-Partes dessa competência da Corte, isto é, é regido por uma cláusula facultativa de jurisdição.

Isto exposto, Flávia Piovesan constata que dos sistemas regionais de proteção dos direitos humanos, o europeu é o que traduz a mais extraordinária experiência de justicialização de direitos humanos por meio da atuação da Corte Europeia, ao assegurar o acesso direto a todo e qualquer indivíduo à sua jurisdição. É dessa forma o sis- 
tema mais democratizado, no sentido em que é o único a permitir o acesso direto de indivíduos, grupo de indivíduos e ONGs à Corte Europeia de Direitos Humanos, de forma incondicionada, haja vista que, no sistema interamericano, o acesso é restrito à Comissão Interamericana e aos Estados, ao passo que no sistema africano, a partir do Protocolo à Carta Africana, o acesso à Corte é limitado à Comissão Africana, aos Estados e às organizações intergovernamentais africanas, sendo previsto por meio de cláusula facultativa, isto é, a depender de declaração expressa do Estado-Parte para tal fim, o acesso de indivíduos e ONGs à Corte Africana. ${ }^{48}$

Importa mencionar também, a título de ilustração e corroborando com o já discorrido,, que muitas das decisões paradigmáticas do sistema europeu advieram de casos submetidos por indivíduos de forma singular, diversamente do sistema interamericano em que o funcionamento do sistema decorre, mormente, da participação da sociedade civil e das ONGs, ao passo que, no sistema africano, as demandas partem, majoritariamente, das ONGs. Isso pode refletir o grau de capilaridade do sistema europeu, que conta com maior conhecimento da população em geral quanto à sua existência e importância ${ }^{49}$.

Em relação ao sistema africano, vislumbramos tal conclusão, ao fazermos um levantamento das comunicações individuais perante a Comissão Africana dos Direitos do Homem e dos Povos, descritas no sítio dessa instituição, o qual as sistematiza pela ordem de submissão, pelo país demandado e pelo artigo da Carta Africana violado. ${ }^{50}$

Analisando-se o Relatório Anual 2009 do Tribunal Europeu dos Direitos do Homem ${ }^{51}$, podemos constatar uma participação notória do indivíduo, demandando de forma singular perante essa instância de proteção, aumentando sua participação de forma exarcebarda após a entrada em vigor do Protocolo no 11 . No gráfico disponível no Relatório atinente às petições atribuídas a uma formação judiciária, atesta-se claramente o aumento anual considerável de petições dirigidas ao Tri-

${ }^{48}$ PIOVESAN, Flávia. Direitos humanos e justiça internacional: um estudo comparativo dos sistemas regionais europeu, interamericano e africano. São Paulo: Saraiva, 2007. p. 134.

${ }^{49}$ Ibidem, p. 136.

${ }^{50}$ Disponível em: </www.achpr.org/english/_info/Decision_ subject.html $>$. Acesso em 20 jul. 2010.

${ }^{51}$ Edição Provisória - Conselho da Europa. Disponível em: <www.ech.coe.int>. Acesso em: 20.07.2010. bunal, chegando nos anos de 2008 e 2009, a ultrapassar o número de pedidos realizados por todo o período de funcionamento da Comissão Europeia dos Direitos do Homem (1995 a 1998).

Em outro gráfico, fornecido pelo citado Relatório Anual referente aos Acordãos proferidos pelo Tribunal, antes e depois da entrada em vigor do Protocolo $n^{\circ} 11$, constata-se que de 1959 até 31 de outubro de 1988, data em que foi extinta a Comissão Europeia, menos de mil acordãos, mais precisamente 837 acordãos, haviam sido proferidos pelo Tribunal em todo o período de existência da Comissão. Nesse período, foram encaminhados à Comissão mais de 128 mil pedidos. Aqui, vale salientar que a Comissão realizou suas tarefas por mais doze meses, contados a partir do dia $1^{\circ}$ de novembro de 1998, para trabalhar com os casos já declarados admissíveis antes da entrada em vigor do Protocolo $n^{\circ} 11$. Em contrapartida, no período subsequente, isto é, posterior ao Protocolo $\mathrm{n}^{\circ}$ 11, de 1999 a 2009, quase 12.000 acordãos foram emitidos pelo Tribunal.

Nesse sentido, para muitos autores, a inclusão da possibilidade de envio de petições individuais diretamente ao Tribunal Europeu teria ocasionado um grande congestionamento de petições nessa instância de proteção e que esse exemplo poderia refletir nos demais sistemas de proteção de direitos humanos, como o africano.

Nessa linha de raciocínio, Maria Luísa Duarte afirma que o caudal imenso de petições individuais está transformando o próprio Tribunal Europeu em um exemplo reiterado de violação do direito a uma apreciação judicial da causa "num prazo razoável". ${ }^{52}$

Entretanto, não foi o acesso direto do indivíduo que acarretou esses problemas ao sistema europeu dos direitos humanos, mas uma série de fatores relativos à própria estrutura do Tribunal Europeu. Diante de tal panorama, surgiu a necessidade de elaboração do Protocolo $\mathrm{n}^{\circ}$ 14, assinado em 13 de maio de 2004 e aberto à ratificação a todos os Estados-Partes da Convenção, que introduz severas mudanças na estrutura do Tribunal Europeu dos Direitos do Homem, com o escopo de garantir um processo mais célere e eficaz. Dentre essas

${ }^{52}$ DUARTE, Maria Luísa. A convenção européia dos direitos do homem: a matriz europeia de garantia dos direitos fundamentais. In: CAMPOS, J. Mota de (Coord.). Organizações Internacionais. 2. ed. [S.1]: F. C. Gubekian, 2006. p. 646. 
mudanças, Maria Luísa Duarte cita a possibilidade de o Tribunal poder decidir em formação de juiz único sobre a inadmissibilidade de uma petição individual, em caráter definitivo, podendo ela ocorrer sob o fundamento da ausência de "prejuízo importante" para o requerente, salvo se o respeito dos direitos previstos na Convenção exigir uma apreciação de fundo. ${ }^{53}$

Do exposto, podemos concluir que a superação das dificuldades que impedem o acesso sem desvios pelo homem às Cortes Regionais, mormente a Interamericana e Africana, é o maior desafio da comunidade internacional, que, gradualmente, conscientiza-se de que o exercício do direito de petição individual é a condição, em uma sociedade democrática, à plena efetividade da Convenção Americana dos Direitos do Homem e a Carta Africana dos Direitos do Homem e dos Povos.

\section{Conclusão}

Como vimos, o indivíduo foi conquistando gradativamente a sua subjetividade internacional ao longo do tempo, possuindo, hodiernamente, capacidade postulatória frente às Cortes Internacionais, mormente as de Direitos do Homem.

Em relação às instâncias de proteção do Sistema Regional Africano de Proteção dos Direitos do Homem e dos Povos, verificamos que o indivíduo apresenta a prerrogativa de submeter comunicações individuais perante a Comissão Africana, embora esse direito não esteja expressamente previsto na Carta Africana dos Direitos do Homem e dos Povos.

No que tange ao acesso do indivíduo à Corte Africana dos Direitos do Homem e dos Povos, verificamos que, embora o Protocolo Adicional à Carta Africana dos Direitos do Homem e dos Povos preveja o direito do indivíduo de submeter um caso ao Tribunal, esse direito só poderá ser exercido se o Estado demandado tiver reconhecido a competência da Corte para apreciar feitos individuais. Como se vê, o acesso do indivíduo se encontra condicionado a uma cláusula facultativa de jurisdição, o que, na verdade, tolhe o exercício desse direito, já que, na prática,

DUARTE, Maria Luísa. A convenção européia dos direitos do homem: a matriz europeia de garantia dos direitos fundamentais. In: CAMPOS, J. Mota de (Coord.). Organizações Internacionais. 2. ed. [S.1]: F. C. Gubekian, 2006. p. 646. nenhum Estado violador teria interesse de reconhecer a competência da Corte para ser demandado. Essa assertiva pode ser ratificada, com o fato de que, até o presente momento, apenas dois Estados-Partes, quais sejam, Burkina Faso e Mali declararam reconhecer a competência da Corte para apreciar e julgar casos submetidos pelo indivíduo.

Outrossim, o Protocolo Adicional, adotado em 11 de julho de 2003, que criou o Tribunal de Justiça da União Africana, não prevê o acesso direto do indivíduo ao Tribunal. Na verdade, apenas parte da doutrina tem entendido que na expressão "terceiras partes", previsto no artigo 18, há alusão à legitimidade individual. De outra banda, parte dos pensadores tem defendido que o referido Protocolo não contempla a possibilidade de demandas individuais perante o Tribunal de Justiça da União Africana, o que, se de fato for, é considerado um grande retrocesso em relação ao Protocolo Adicional à Carta Africana, a qual, embora condicione o acesso do indivíduo, ao menos reconhece a possibilidade de ele submeter casos perante a Corte Africana dos Direitos do Homem e dos Povos.

Ademais, o Protocolo relativo ao Estatuto do Tribunal Africano de Justiça e Direitos Humanos, de 2008, que prevê a fusão do Tribunal Africano dos Direitos do Homem e dos Povos com o Tribunal de Justiça da União Africana, aduz que o indivíduo só pode apresentar petições contra os Estados que tenham feito uma declaração aceitando e reconhecendo a competência do Tribunal de Justiça para fazê-lo, nos termos do artigo 30, alínea f, do Protocolo Único.

Dessa forma, verificamos que mesmo nesse último Protocolo, mais atual, mas que ainda não se encontra em vigor, o acesso do indivíduo ao Tribunal se encontra condicionado ao alvedrio do Estado-Parte violador, o que, na prática, torna ilusória a capacidade postulatória do indivíduo.

É necessário, portanto, que a sociedade civil, os Estados e a União Africana busquem intensificar esforços no sentido de incentivar os Estados-Partes a ratificarem o Protocolo Único bem como fazer a declaração permitindo o acesso do indivíduo ao Tribunal, haja vista que essa é condição, em uma sociedade democrática, a plena efetividade dos instrumentos de proteção dos direitos do homem e dos povos na África.

Faz-se mister mencionar ainda que o Tribunal não irá satisfazer as expectativas dos africanos se a União 
Africana não fornecer um suporte material e moral que lhe permita funcionar como instituição independente e significativa que deve ser. Em última análise, a Corte Africana só ganhará em legitimidade, assegurando um alto nível por meio da acessibilidade e da transparência dos seus procedimentos, da qualidade e da imparcialidade de suas conclusões.

Por fim, após analisarmos os três sistemas regionais de proteção dos direitos do homem, pudemos concluir que o sistema europeu é o mais democrático, haja vista que assegura o acesso direto a todo e qualquer indivíduo à sua jurisdição. Por outro turno, no sistema interamericano, o acesso é restrito à Comissão Interamericana e aos Estados, ao passo que no sistema africano, a partir do Protocolo à Carta Africana, o acesso à Corte é limitado à Comissão Africana, aos Estados e às organizações intergovernamentais africanas, sendo previsto o acesso do indivíduo à Corte Africana, por meio de cláusula facultativa, isto é, a depender de declaração expressa do Estado Parte para tal fim.

\section{Referências}

AFRICA UNION. [Site]. Disponível em: <www.africaunion.org>.

AFRICAN COURT ON HUMAN AND PEOPLES' RIGHTS. [Site]. Disponível em: <www.african-court.org >. Acesso em: 13 jun. 2010.

AMNESTY INTERNATIONAL. Proteger les droits humains: outils et mécanismes juridiques internatonaux. [S.1]: Éditions du Juris-Classeur, 2003.

BARRETO, Irineu Cabral. A convenção européia dos direitos do homem anotada. 3. ed. Coimbra: Coimbra Ed., 2005.

BEKKER, Gina. The African Court on Human and Peoples' Rights: Safeguarding the Interests of African States. Journal of African Law, v. 51, n. 1, p. 151-172, 2007.

BRITO, Wladimir. Direito internacional público. Coimbra: Coimbra Ed., 2008.

COUILLARD, Valérie et al. The fight for Human Rights in Africa: perspectives on the African Commission on Human and Peoples Rights. [S.1: s.n], 2008.
DOEBBLER, Curtis F. J. The African Union and the new pan-africanism: rushing to organize or timely shift: A complex ambiguity: the relationship between the African Commission on Human and Peoples' Rights and Other African Union Initiatives Affecting respect for Human Rights. Transnational Law and Contemporary Problems. n. 13, 2003.

DUARTE, Maria Luísa. A convenção européia dos direitos do homem: a matriz europeia de garantia dos direitos fundamentais. In: CAMPOS, J. Mota de (Coord.). Organizações Internacionais. 2. ed. [S.1]: F. C. Gubekian, 2006.

GARCIA, Emerson. Proteção internacional dos direitos humanos: breves reflexões sobre os sistemas convencional e não-convencional. 2. ed. Rio de Janeiro: Lumen Juris, 2009.

MACHADO, Jónatas E. M. Direito internacional: do paradigma clássico ao pós-11 de setembro. 3. ed. Coimbra: Coimbra Ed., 2006.

MARTORANA, Carolyn Scanlon. The new African Union: will it promote enforcement of the decisions of the African Court of Human and Peoples Rights? George Washington International Review, n. 40, 2008.

MELLO, Celso D. de Albuquerque. Curso de direito internacional público. Rio de Janeiro: Renovar, 2004.

MOCO, Marcolino José Carlos. Direitos humanos e seus mecanismos de proteção: as particularidades do sistema africano. Coimbra: Almedina, 2010.

MOHAMED, Abdelsalam A. Individual and NGO participation in Human Rights litigation before the African Court of Human and People's Rights: Lessons from the European and Inter-American Couts of Human Rights. Michigan State University-DCL Journal of International Law, Michigan, 1999.

MUBIALA, Mutoy. Laccès del'individu à la Cour Africaine des droits de l'homme et des peuples. In: PROMOTING justice, human rights and conflict resolution through international law: liber amicorum lucius caflisch. 2007. p. 369-378.

MUBIALA, Mutoy. Le système régional africain de protection des droits de l'homme. Bruxelles: Établissements Émile Bruylan, 2005.

MURRAY, Rachel. A comparison between the African and European Courts of Human Rights. African Human Rights Law Journal, v. 2, n. 2, p. 195-227, 2002. 
MURRAY, Rachel. Decisions by the African Commission on Individual Communications under the African Charter on Human and Peoples Rights. International \& Comparative Law Quarterly. Local, v. 46, issue 2, p. 412434, 1997.

MURRAY, Rachel. The African Charter on Human and Peoples Rights 1987-2000: an overview of its progress and problems. African Human Rights Law Journal, Local, v. 1, n. 1, p. 1-18, 2001.

MUTUA, Makau. The African Human Rights Court: A two-legged stool? In: HUMAN rights quarterly: the Jonhs Hopkins University. 1999. .

ODINKALU, Anselm Chidi. Proposals for the review of the rules of procedure of The African Commission of Human and People Rights. In: HUMAN Rights Quarterly. 1993.

ODINKALU, Anselm Chidi; CHRISTENSEN, Camilla. The African Commission on Human and People's Rights : The development of its non-states Communication Procedures. In: HUMAN Rights Quarterly, The Johns Hopkins University. 1998.

OUGUERGOUZ, Fatsah. The African Charter on Human and Peoples' Rights: a comprehensive agenda for human dignity and sustainable democracy in Africa. 2003.

OURGUEGOUZ, Fatsah. Separate opinion of judge Fatsah Ouguergouz. Disponível em: <www.african-court. org/fileadmin/documents/Court/Latest_Judgments/ English/SEPARATE_OPINION_OF_JUDGE_FATSAH_ OUGUERGOUZ.EN.PDF>. Acesso em: 15 jun. 2010.

PIOVESAN, Flávia. Direitos humanos e justiça internacional: um estudo comparativo dos sistemas regionais europeu, interamericano e africano. São Paulo: Saraiva, 2007.
SARKIN, Jeremy. The role of the United Nations, the African Union and Africa's Sub-Regional Organizations in Dealing with Africa's Human Rights Problems: connecting humanitarian intervention and the responsibility to protect. Journal of African Law, v. 53, n. 1, p. 1-33, 2009.

TRINDADE, Antônio Augusto Cançado. A Personalidade e Capacidade Jurídicas do Indivíduo como Sujeito do Direito Internacional. In: ANNONI, Danielle (Org.). Os novos conceitos do novo direito internacional: cidadania, democracia e direitos humanos. Rio de Janeiro: América Jurídica, 2002.

UDOMBANA, Nsongurua J. An African Human Rights Court and an African Union Court: a needful duality or a needless duplication? Brooklyn Journal of International Law, n. 28, 2003.

UDOMBANA, Nsongurua J. So far, so fair: the local remedies rule in the jurisprudence of the African Commission on Human and Peoples' Rights. American Journal of International Law, n. 97, 2003.

UMOZURIKE, U. O. The African Charter on Human and People's Rights, Nigerian Institute of Advanced Legal Studies. n. 25, 1992.

UMOZURIKE, U. O. The African Charter on Human and People's Rights: Suggestions for more effectiveness. Annual Survey of International \& Comparative Law: golden gate university school of law, spring 2007.

VILJOEN, Frans. A Human Rights Court for Africa and Africans. Brooklin Journal of International Law, 2004.

WRIGHT, Rebeca. Finding an Impetus for Institutional Change at the African Court on Human and People's Right. Berkeley Journal of International Law, n. 24, 2006. 